\title{
A GESTÃO DE RH COMO \\ ESTRATÉGIA EMPREENDEDORA: \\ UM ESTUDO COM PEQUENAS E MÉDIAS \\ EMPRESAS DA CIDADE DE JOÃO PESSOA - PB
}

THE MANAGEMENT OF HR AS AN ENTREPRENEURS STRATEGY: A STUDY

WITH SMALL AND MEDIUM ENTERPRISES OF THE CITY OF JOÃO PESSOA - PB

Janayna Souto Leal'

Jordania Gouveia Batista ${ }^{2}$

João Batista Soares Neto ${ }^{3}$

\section{RESUMO}

No contexto atual, a Gestão de RH procura se envolver com diversos setores das organizações, trazendo resultados eficazes e pertinentes, desenvolvendo, assim, comportamentos empreendedores dos seus gestores. Logo, este trabalho tem como objetivo geral analisar como a gestão de RH pode representar uma estratégia empreendedora para pequenas e médias empresas da cidade de João Pessoa PB. Para tal, foi adotada uma abordagem qualitativa e a coleta de dados realizouse através de um roteiro de entrevistas estruturado com a participação de 4 gestores da cidade de João Pessoa - PB. O método escolhido foi o da análise de conteúdo proposta por Bardin (2011). A análise dos dados baseou-se nas seguintes categorias: inovação, autonomia, propensão a tomar riscos, pró-atividade e agressividade competitiva. Como resultado, percebe-se que as técnicas de orientação empreendedora vêm sendo cada vez mais empregadas pelos gestores de RH. Para concluir, o trabalho apresenta limitações e contribuições para estudos futuros.

Palavras-chave: Gestão de RH. Orientação empreendedora. Pequenas e Médias Empresas.

\section{ABSTRACT}

In the current context, HR Management seeks to engage with diverse sectors of the organizations, bringing effective and pertinent results, thus developing entrepreneurial behaviors of its managers. Therefore, this work aims to analyze how HR management can represent an entrepreneurial strategy for small and medium enterprises in the city of João Pessoa - PB. For this, a qualitative approach was

1 Mestre em Administração pela Universidade Federal da Paraíba (UFPB). Docente do Centro Universitário de João Pessoa (UNIPÊ). E-mail: leal.janayna@gmail.com

2 Graduada em Administração pelo Centro Universitário de João Pessoa (UNIPÊ). E-mail: jordania-vc@hotmail.com

3 Doutor em Administração pela Universidade Federal da Paraíba (UFPB). Docente da Universidade Federal da Paraíba (UFPB).

E-mail: jnetojp@gmail.com

\section{INTER SCIENTIA}

REVISTA INTERSCIENTIA | V. 7 | N. 1 | P. 115-139 | JAN-JUN/2019 
adopted and data collection was carried out through a structured interview script with the participation of 4 managers from the city of João Pessoa - PB. The method chosen was that of the content analysis proposed by Bardin (2011). Data analysis was based on the following categories: innovation, autonomy, propensity to take risks, proactivity and competitive aggressiveness. As a result, it is perceived that the techniques of entrepreneurial orientation have been increasingly used by $H R$ managers. To conclude, the paper presents limitations and contributions for future studies.

Keywords: HR management. Entrepreneurial Guidance. Small and Medium Enterprises.

\section{INTRODUÇÃO}

O surgimento da revolução industrial e as dificuldades enfrentadas em suas atividades, tais como, contratações, demissões, avisos/advertências, ajustes de salários, entre outros, no início no século XX, serviram como ponto de partida para o estudo das relações humanas, tendo como base na atuação de mediação de conflitos entre os objetivos da organização e as pessoas incompatíveis com os objetivos estabelecidos (MACORE, 2016).

No entanto, os Recursos Humanos, segundo o autor, foram evoluindo e, com o passar dos anos, já não eram utilizados apenas para a gestão de conflitos e para selecionar, contratar e demitir funcionários, mas também para administrar as pessoas junto a legislação trabalhista. Atualmente, o RH possui uma função bem mais estratégica, pois além de criar uma sinergia e desenvolvimento dos funcionários, utiliza-se maior comunicação, novas tecnologias, diversidade, valorização dos funcionários e de outros fatores. Nesse contexto, surge o RH estratégico que procura se integrar com os demais setores da empresa, entregando assim resultados mais eficientes e adequados à organização, auxiliando, na maioria das vezes, comportamentos engajados e empreendedores.

Nesse sentido, de acordo com Dornelas (2008, p.22), o "empreendedorismo é o envolvimento de pessoas e processos que, em conjunto, levam à transformação de ideias em oportunidades". Logo, ao iniciar um investimento ou negócio, alguns setores e departamentos acabam por ser esquecidos ou negligenciados. Dentre eles, pode-se destacar o RH, um setor vital para qualquer organização, funcionando como um portal direto de comunicação entre a empresa e os seus colaboradores.

Segundo o último relatório de Sobrevivência das empresas no Brasil, fornecido pelo Serviço Brasileiro de Apoio às Micro e Pequenas Empresas (SEBRAE) (2016), utilizando como referência as empresas brasileiras constituídas em 2012, foi possível perceber que, na cidade de João Pessoa, a taxa de sobrevivência das 
empresas aos dois primeiros anos de mercado foi de $76,3 \%$, enquanto que a taxa de mortalidade foi equivalente à $23,7 \%$ no mesmo período.

Esses dados até parecem "animadores", porém quando comparado a outras capitais do país, a cidade ocupa o 12 lugar e no Nordeste o $6^{\circ}$, ou seja, em termos de competitividade dão resultados que precisam ser melhorados. Segundo a pesquisa, diversos fatores podem acarretar na sobrevivência ou mortalidade das empresas, tais como: experiência no ramo; planejamento e gestão do negócio; capacitação dos donos em gestão empresarial, entre outros.

Dessa forma, as práticas de atuação do gestor, quando bem executadas, podem se tornar medidas empreendedoras em várias áreas funcionais das organizações, independentemente do seu porte e isso influi também na área de Gestão de Recursos Humanos.

Nesse sentido, o presente estudo abre a seguinte problemática: como a gestão de RH pode representar uma estratégia empreendedora para os gestores de pequenas e médias empresas da cidade de João Pessoa - PB?

Para responder essa questão, o artigo tem como objetivo geral analisar como a gestão de RH pode representar uma estratégia empreendedora para pequenas e médias empresas da cidade de João Pessoa - PB. Para tal, como objetivos específicos procurou-se identificar as práticas de Gestão de RH mais utilizadas pelos gestores responsáveis pelo setor, verificar as ações empreendedoras que têm relação com os Recursos Humanos e examinar a relação entre empreendedorismo e Gestão de RH no contexto das pequenas e médias empresas.

Dessa forma, o artigo segue uma sequência fazendo um levantamento bibliográfico no referencial teórico, em seguida explica o percurso metodológico e, por fim, realiza a análise das entrevistas e conclui todo o processo com as considerações finais.

\section{REFERENCIAL TEÓRICO}

Nesta seção serão desenvolvidas as referências literárias que tem por objetivo tratar e discutir o uso da gestão de recursos humanos como estratégia de empreendedorismo. Para tal, será trabalhado: a gestão de recursos humanos e o seu processo evolutivo da gestão de recursos humanos, o empreendedorismo e a sua evolução e aplicabilidade e, por fim, o Gestor estratégico e a orientação empreendedora nas pequenas e médias empresas.

\section{A GESTÃO DE RECURSOS HUMANOS E O SEU PROCESSO EVOLUTIVO}

As organizações estão em constante mudança e evolução, sejam elas econômicas, tecnológicas ou até mesmo mercadológicas, podendo causar as 
mais diversas transformações em seus colaboradores, tanto no aspecto pessoal, quanto no profissional. Dessa forma, o setor de Recursos Humanos precisa estar acompanhando tais alterações, adequando-se ao seu papel. Durante o século XX, as organizações passaram por três momentos relevantes, momentos estes que são expostos com maior detalhamento por Chiavenato (2009): a Era da Industrialização Clássica, a Era da Industrialização Neoclássica e a Era da Informação.

O primeiro momento ficou conhecido como a Era da industrialização Clássica (1900 a 1950), tendo seu início durante a Revolução Industrial, se caracterizando pelo Departamento Pessoal e logo após, pelas suas relações industriais. O departamento pessoal (DP) possuía como obrigações o cumprimento da parte legal e burocrática da organização, ou seja, os processos de admissão, as folhas de pagamento, controle de férias, controle e aplicação de advertências, dentre outras atividades. Além disso, o DP acabou assumindo mais uma responsabilidade junto às organizações, ficando também responsável pelo relacionamento da organização junto aos sindicatos.

De acordo com Chiavenato (2009), neste período, as estruturas organizacionais típicas eram reconhecidas por apresentarem formato piramidal e centralizador, pelo estabelecimento de regras e regulamentos interno para disciplinar e padronizar o comportamento dos participantes. Predominava uma forte cultura de tradições organizacionais, em que as pessoas ainda eram consideradas como máquinas e capitais da organização. Neste período, as mudanças ocorriam de forma lenta.

O segundo momento ficou conhecido como a Era da Industrialização Neoclássica (1950 a 1990), tendo seu início no final da Segunda Guerra Mundial (1950) e perdurou até o ano de 1990. Nesse contexto ocorreram algumas mudanças significativas e previsíveis, como o caso das transações comerciais e a presença de uma maior concorrência entre as empresas. O Setor de Recursos Humanos, ainda responsável pelas atividades operacionais e burocráticas existentes, acabou incorporando mais algumas atividades, como o recrutamento e seleção, treinamento e desenvolvimento e a segurança do trabalho e higiene.

Para Marras (2011), durante os anos de 1950 e 1965, surgiu nas organizações a presença dos administradores de pessoal. As organizações começaram a dar um enfoque em recrutamento de profissionais com currículos mais amplos, intencionando admissões de profissionais com visão humanista. De 1965 a 1985, as empresas consolidaram o perfil dos gestores de RH como administradores de empresas. Logo, as organizações começaram a buscar e exigir profissionais com conhecimentos mais especializados e legais.

Durante o ano de 1970, foi instituída a Teoria do Capital Humano, possuindo como derivação as teorias econômicas neoclássicas, apresentada em duas perspectivas. A primeira com enfoque na capacitação dos trabalhadores e, consequentemente, em um aumento de produtividade. Para a segunda perspectiva 
foi dado um destaque nas estratégias individuais de cada trabalhador, de forma a avaliar o seu custo-benefício. Próximo ao final do século XX, a Teoria do Capital Humano foi prestigiada, quanto às suas práticas e aos debates relacionados à segmentação do mercado de trabalho, polivalência e a flexibilida de do trabalhador, assim como a qualidade total e preferência dos consumidores (CATTANI, 1997; DEMO, 2010).

E por fim, o terceiro momento que ficou conhecido como a Era da Informação (1990 até os dias atuais). Neste momento, surgiu um conjunto de abordagens e teorias, dentre elas pode-se destacar a Teoria do Caos e da Complexidade, onde pressupõe situações e comportamentos nas organizações que operam com sistemas dinâmicos e não lineares. No mesmo ano surgiu a Administração do Conhecimento, com a origem nas empresas que manuseiam e utilizam um grande fluxo de informações (ALBUQUERQUE e LEITE, 2009).

A Era da Informação é marcada por um conjunto de transformações marcadas pela imprevisibilidade e velocidade. Esta era caracteriza-se pela capacidade de disseminação de informações em alta velocidade para todo o mundo (CHIAVENATO, 2009). Estas transformações geraram algumas mudanças na estrutura e conceituação das organizações, dentre elas pode-se citar: a estrutura organizacional, onde passou a ser mais ágil, flexível e totalmente descentralizada, dando ênfase nas equipes multifuncionais; a cultura organizacional, utilizando-se da teoria Y, dado uma ênfase na mudança e na inovação, valorizando o conhecimento e a criatividade. O ambiente organizacional é mutável, contando com grandes e intensas alterações. De acordo com Tegon (2015), nesta era as pessoas passaram a ser reconhecidas como seres humanos proativos, inteligentes e motivados, de forma a conciliar a relação de liberdade e comprometimento.

Tais transformações citadas anteriormente afetaram a gestão de pessoas, de forma a propor um novo conjunto de desafios aos antigos administradores de $\mathrm{RH}$, desafios estes que compreendem e dão uma ênfase menos burocrática, passando a assumir um papel de alavancagem e crescimento de um dos mais preciosos bens das organizações, o capital humano.

Desta forma pode-se dizer que tecnologia da informação é resultado da globalização mundial, como consequência há um aumento da competitividade entre as organizações, de forma que as organizações realizam as mais diversas mudanças para maximizar os seus rendimentos, alterando inclusive as suas disposições estruturais (departamentos, cargos e funções), tornando-as cada vez mais flexíveis, de forma que eles se adaptam cada vez mais as mudanças que ocorrem no mercado e na maneira de empreenderem a sua organização. 


\section{EMPREENDEDORISMO: EVOLUÇÃO E APLICABILIDADE}

Definir empreendedorismo não é uma tarefa fácil, pois existem diferentes correntes de pensamentos que apresentam suas definições conforme suas diretrizes e levam em conta diversos fatores, sendo eles do individual ao empresarial, e abrangendo os níveis ambientais (MAS-TUR, 2015).

De acordo com Landström, Harirchi, Aström (2012), provavelmente a função do empreendedorismo é tão antiga quanto o intercâmbio e o comércio entre os indivíduos na sociedade, contudo este conceito ainda não era discutido. Somente a partir da evolução dos mercados econômicos, os cientistas se interessaram pelo fenômeno.

Ao analisarem a evolução do empreendedorismo como campo de pesquisa, os autores destacaram Richard Cantillon (1755) como o primeiro autor a apresentar um conceito de empreendedorismo voltado a um aspecto econômico. Contudo, a conceituação do empreendedor e de sua estrutura só veio a se fortalecer e se tornar análoga, como um campo de pesquisa, a partir do século XX.

Eles ainda constataram que o pensamento empreendedor se divide em três fases, sendo elas: a fase Econômica, a das Ciências Sociais e a fase do Management (estudos gerenciais). A fase econômica ficou destacada pelos trabalhos e estudos realizados por Frank Knigth e Josehp Schumpeter, considerando o empreendedor como um indivíduo que trabalha em ambientes de inúmeras incertezas, provando sempre ser agente de inovação. Para Schumpeter (1950), um empreendedor é uma pessoa que deseja e é capaz de converter uma nova idéia e/ou invenção em uma inovação de sucesso. Já na fase das Ciências Sociais, o empreendedor é caracterizado por um conjunto de traços comportamentais, buscando o conjunto de características que o estruturam e diferenciam de um ser humano normal (McClelland, 1972). Por fim, a fase do Management, na qual o empreendedorismo acaba por ganhar um aspecto mais estratégico, em que um grupo de autores adota-o como campo de estudo. Logo, o empreendedorismo é marcado por um conjunto de fases que contempla autores e pontos de vistas bem variados, surgindo assim novas conceituações e campos de estudo quanto a sua natureza, os seus princípios e o ambiente em que está empregado.

Segundo Bruyat e Julien (2000), as principais visões defendidas pelos economistas em relação ao empreendedor, foram: que o empreendedor é uma pessoa que assume os riscos e incertezas; organiza e coordena os fatores de produção e a visão de um agente inovador. Já para Druker (2001), os economistas não conseguiram identificar as causas/motivos e características que tornavam os empreendedores eficazes, considerando o empreendedorismo como um fator meta-econômico, ou seja, que possui certa influência na economia, porém não faz parte da mesma. 
Já na perspectiva dos sociólogos, o contexto em que os indivíduos estavam inseridos, os grupos sociais, as experiências e como tais fatores influenciavam na escolha de empreender, como fatores determinantes. O importante não era apenas considerar os valores e aspirações do empreendedor, mas também do impacto causado pela sociedade juntamente com outras instituições (CASSON; YEUNG; BASU; WADESON, 2006; SELTISIKAS; LYBEREAS, 1996). De acordo com Campos e Duarte (2013), foi explorada a importância do ambiente social e/ou coletivo do trabalho do empreendedor, em relação a definição tradicional, onde se define como aquele que inova e que possui habilidade de antecipar situações. Sendo assim, "a habilidade principal requerida do empreendedor não é a do visionário nem a do planejador, mas, sim, a do agenciador, do coordenador e do negociador de cooperação e colaboração" (CAMPOS; DUARTE, 2013, p. 21).

Por fim, na visão do Management, ou também conhecido como estudos gerenciais, os estudos estão voltados ao "como" o empreendedor atua (STEVENSON; JARILLO, 1990), ou seja, aos seus comportamentos gerenciais. Neste momento, Gartner (1985) propõe aos pesquisadores observarem os empreendedores no processo de criação das organizações. Para Christensen, Ulhoi e Madsen (2002), o empreendedorismo é parte essencial na criação de novas organizações. Durante esse mesmo contexto, Bruyat e Julien (2000), apontam a existência de duas fortes tendências no que cerca o empreendedorismo, em que a primeira delas compreende o empreendedor como um indivíduo que cria e desenvolve novos negócios e a segunda que entende o empreendedor como um inovador que altera a economia.

Existem os mais distintos tipos de empreendedores e empresas, onde se entende a abertura de um novo negócio como algo complexo e com diversos direcionamentos, que podem variar de acordo com o ambiente em que está inserido. A abertura de uma empresa contempla na visão do autor, quatro aspectos: Indivíduo (que é a pessoa envolvida no início do novo negócio), Organização (características e o tipo de empresa que está iniciando as atividades), Processo (contempla as ações desempenhadas pelo indivíduo para iniciar o empreendimento) e o Ambiente (conjunto de elementos/situações que irão influenciar os direcionamentos e atividades da empresa) (GARTNER, 1985).

Por se tratar de um processo complexo, envolvendo vários aspectos e fatores tanto internos, quanto externos, alguns autores não restringem o empreendedorismo como um fator individual, mas sim como coletivo, "essas diferentes influências fazem do empreendedor um ser plural e coletivo que se constrói aos poucos e determina as razões que levarão o indivíduo mais ou menos preparado a tornar-se um empreendedor" (JULIEN, 2010, p. 17).

Segundo Grégoire et. al (2006), em relação ao estudo e as pesquisas do empreendedorismo no que compreende o nível da organização, houve 
um crescimento neste quesito tanto em dimensão, quanto em profundidade, constituindo assim um fator importante e um consistente eixo de estudo.

Partindo-se do princípio de que o mundo empresarial contemporâneo vem sendo caracterizado por um ambiente cada vez mais competitivo, globalizado e com frequentes mudanças, fazendo com que as empresas desenvolvam as suas capacidades de adaptaçãojunto ao mercado e com uma conduta empreendedora e aberta para a descoberta de novas oportunidades (HAYTON, 2005). Entre essas oportunidades pode-se destacar as próprias áreas funcionais das organizações como maneira de impulsionar e potencializar o crescimento das mesmas com os seus ativos. Entre as áreas mais exploradas, encontra-se a dos Recursos Humanos, sendo visualizada como uma chance de, estrategicamente, o gestor desenvolver, com uma orientação empreendedora, o que as empresas têm de mais valioso: o seu capital humano.

\section{O GESTOR ESTRATÉGICO E A ORIENTAÇÃO EMPREENDEDORA NAS PEQUENAS E MÉDIAS EMPRESAS}

A Gestão de Recursos Humanos veio de um processo gradativo de evolução em que o gestor teve que transformar-se para acompanhar as mudanças pelas quais o mercado passou e continua a passar. Um novo papel surgiu, alinhado e muito mais próximo ao que é solicitado e cobrado no cenário mercadológico e que condiz com o modus operandi adotado pelas organizações no contexto de atuação profissional. Sendo assim, diante desse cenário, surge o novo gestor de RH: o gestor estratégico.

O gestor estratégico de pessoas além de exercer as suas atividades fundamentais, neste momento passa a compreender os seus colaboradores, as suas necessidades e os seus processos de trabalho por meio de uma visão sistêmica. Estes gestores exercem as suas responsabilidades utilizando da detecção de talentos, do gerenciamento de conflitos, aplicação de treinamentos e busca pela máxima performance dos seus colaboradores e competências necessárias para o seu desempenho profissional.

Conforme Dias (2015) afirma, o gestor de pessoas "não atua mais como um 'tirador de pedidos', mas como um ponto estratégico nas reuniões de tomada de decisão". De forma que para conseguir realizar as intervenções com a maior eficiência e eficácia possível, primeiramente, são necessários que se tenha conhecimento dos negócios da empresa, e em um segundo momento, se faz necessário que o gestor tenha uma visão holística e com foco nos resultados, de forma que assim possa auxiliar a empresa a alcançar os seus objetivos.

Em meio a este panorama, surge o conceito da Orientação Empreendedora (OE) de Miller (1983), no que se refere a abordagem do empreendedorismo ao nível das organizações. A OE contempla a aprendizagem organizacional, a criatividade e o 
interesse individual em promover mudanças ao ambiente de trabalho (HAYTON, 2005). Desta forma, a OE pode ser considerada como um conjunto de capacidades e ações organizacionais para que haja a inovação, renovação e a exposição aos riscos.

Os fundamentos da Orientação Empreendedora (OE), tem como origem os trabalhos realizados por Longenecker e Schoen (1975), que fundamentaram três componentes fundamentais desta linha de pensamento, sendo elas: a Inovação, Autonomia e a Propensão a tomar riscos. Onde a Inovação, pressupõe que o empreendedorismo está ligado a ações inovadoras e/ou criativas, que podem abranger a criação de novos produtos, serviços ou até mesmo mercados. Já a Autonomia, compreende o direito do empreendedor poder desfrutar de suas próprias decisões, sejam elas na escolha de suas estratégias, uso de insumos, projeção de metas e objetivos, e a busca por novas oportunidades. Por fim, a Propensão de tomar riscos está ligada a toda e qualquer iniciativa que envolva algum grau de risco, desta forma, quanto maior for o fator de inovação, maior será o grau de incerteza.

Além dos fundamentos descritos anteriormente, Miller (1983) ainda propôs a inclusão de um novo componente, a "pró-atividade", tendo como justificativa que a "implementação do que for necessário para antecipar e agir sobre uma oportunidade empreendedora, com perseverança, adaptabilidade e tolerância a riscos". Além do autor citado, Covin e Slevin (1989), sugeriram um quinto elemento como componente da OE. a "agressividade competitiva". A mesma trata-se da capacidade da organização alocar recursos a fim de responder as disposições dos concorrentes e do mercado em que atua.

Desta forma, a Orientação Empreendedora pode então ser definida como um conjunto de componentes-chaves, planejamentos, execuções e atividades de tomada de decisão que despertam às organizações a iniciarem novos empreendimentos (LUMPKIN; DESS, 1996).

No que denota a aplicação e uso da OE nas organizações, não existe uma receita ou dosagem exata a ser utilizada na sua implantação. Os gestores e líderes precisam analisar o contexto que se encontram inseridos, verificar o mercado e suas inúmeras variáveis que o compõem, para que desta forma seja possível definir os seus planejamentos e estratégias, de modo que lhe consiga oferecer os melhores resultados para a sua organização. Assim, a OE pode se estabelecer nas mais diversas segmentações e estruturas, variando por meio das dimensões, sejam elas a área de atuação, o ambiente, o mercado, entre outros aspectos.

De acordo com Hashimoto (2009), a liderança empreendedora promove o comportamento empreendedor entre os líderes e seus colaboradores, tendo como base a capacidade de geração de soluções não convencionais para problemas existentes no cotidiano, mesmo que tais ações e mudanças possam acarretar em riscos e incertezas inerentes da utilização de formas diferentes e criativas, o que acarreta em um cuidado redobrado com empresas de pequeno e médio porte, já 
que as mesmas possuem uma estrutura mais frágil em relação às suas concorrentes de grande porte.

O líder empreendedor possui uma visão crítica e apurada em relação as suas atitudes e posicionamentos perante cada componente da equipe, tendo como base a sua autoconfiança, valorização do capital humano da organização, comprometimento, a sinergia e, principalmente, a colaboração mútua entre as pessoas (ROBBINS, 2002). Desta forma, um gestor que apresenta traços de liderança empreendedora influencia tanto os colaboradores e membros da equipe, quanto às estratégias adotadas pela organização (TARABISHY; SOLOMON; FERNALD; SASHKIN, 2005). Um bom gestor sabe que, para atingir os seus objetivos, é necessário mais do que estar apenas presente junto aos seus colaboradores, é imprescindível o reconhecimento, a oportunidade de crescimento para estas pessoas, assim como a sinergia entre a equipe, seja tanto em pequenas, quanto em grandes empresas.

A presença de um gestor estratégico que possui e utiliza da liderança empreendedora se faz necessária em todas as empresas, inclusive nas empresas de pequeno porte. Segundo o Serviço Brasileiro de Apoio às Micro e Pequenas Empresas (SEBRAE), é considerado empresa de pequeno porte (EPP) todo o empreendimento com faturamento bruto anual entre $R \$ 360$ mil reais até $R \$ 4$ milhões e 800 mil. Além dos dados fornecidos pelo SEBRAE, é possível classificar as empresas como EPP em relação ao número de funcionários que a compõe, neste caso, utilizando a base fornecida pelo Instituto Brasileiro de Geografia e Estatística (IBGE), para empresas do segmento industrial, está entre 20 a 99 funcionários, já para as empresas do segmento de comércio e serviços, está entre 10 e 49 funcionários.

Já no que contempla as empresas de médio porte, segundo o SEBRAE, as mesmas se enquadram quando possuem faturamento bruto anual igual ou inferior a $\mathrm{R} \$ 360$ mil reais. Segundo o IBGE, pode-se classificar as empresas como ME em relação ao número de funcionários da seguinte forma: para as empresas do segmento industrial, está entre 100 a 499 funcionários e para as de segmento de comércio e serviços, está entre 50 a 99 funcionários.

Através das disposições apresentadas, pode-se estabelecer então uma relação de extrema importância entre a orientação empreendedora (OE), o gestor estratégico e o segmento das pequenas e médias empresas, pois através das dimensões oferecidas pela OE e por sua implantação por parte das organizações e gestores é possível traçar e alcançar os objetivos almejados, dando ênfase aos gestores que dispõe da liderança empreendedora com características profissionais adequadas para esse tipo de organização, facilitando estas com os meios necessários para o alcance dos seus objetivos. Para Tarabishy, Solomon, Fernald e Sashkin (2015), um gestor que está presente, junto a sua equipe e que promove oportunidades, reconhece e valoriza o capital humano da sua organização, lidera com maior respeito e eficiência, podendo influenciar tanto os seus colaboradores 
quanto às estratégias adotadas pela organização, resultando também para as de pequeno e médio porte.

\section{METODOLOGIA}

O estudo tem o propósito de verificar a Gestão de Recursos Humanos como estratégia empreendedora nas pequenas e médias empresas na cidade de João Pessoa. O contexto citado foi escolhido devido à representatividade que estes portes possuem no cenário empresarial na Paraíba, podendo-se analisar como as práticas de Gestão de RH podem ser um diferencial na aplicação empreendedora destas organizações.

Partindo desse princípio, optou-se por utilizar a abordagem qualitativa que, de acordo com Richardson $(2015$, p. 90 ) a abordagem qualitativa pode ser definida como uma tentativa de "compreensão detalhada dos significados e características situacionais apresentadas pelos entrevistados, em lugar da produção de medidas quantitativas de características ou comportamentos".

Uma das preocupações desta investigação foi manter a privacidade dos gestores e, consequentemente, das empresas. Dessa forma, decidiu-se por utilizar pseudônimos, ou seja, nomes fictícios, para que os respondentes se sentissem confortáveis para participar das entrevistas, conforme pode ser observado no quadro 1.

Para coleta de dados foi utilizado um roteiro de entrevistas estruturado que, segundo o autor Marras (2017, p. 66) é uma entrevista cujo qual utiliza-se de processos "previamente planejados do "que" e "como" fazer ao longo de todo o tempo da entrevista", de maneira que não haja oportunidade de inclusão de novos apontamentos durante a entrevista. Para melhorar a questão da conveniência para os gestores entrevistados, já que estes possuem agendas bastante preenchidas devido aos seus compromissos e demandas, optou-se em realizar a entrevista por meio do ambiente digital, mais especificamente via e-mail, de modo a oferecer mais comodidade e praticidade na obtenção das respostas.

Para a escolha dos sujeitos participantes da pesquisa, decidiu-se por entrevistar 4 gestores de empresas de pequeno e médio porte da cidade de João Pessoa - PB de áreas distintas com a intenção de proporcionar uma maior diversificação de cenários aplicados para a mesma temática, ou seja, como setores diferentes utilizam a Gestão de RH como estratégia empreendedora, de forma a também oferecer uma visão comparativa entre os dois portes empresariais. As entrevistas foram realizadas no período de 18 de outubro de 2108 à 07 de novembro de 2018. No quadro abaixo, segue o perfil dos 4 entrevistados: 
Quadro 1: Perfil dos entrevistados

\begin{tabular}{|c|c|c|c|c|c|}
\hline Entrevistados & Gênero & Idade & Escolaridade & Segmento de Atuação & Porte da Empresa \\
\hline Entrevistado 1 & Feminino & 28 anos & Graduada & Direção automotiva & Pequeno \\
\hline Entrevistado 2 & Masculino & 40 anos & Pós-graduado & Alimentação & Pequeno \\
\hline Entrevistado 3 & Masculino & 33 anos & Pós-graduado & Tecnologia & Médio \\
\hline Entrevistado 4 & Feminino & 39 anos & Pós-graduada & Calçadista & Médio \\
\hline
\end{tabular}

Fonte: Elaboração própria (2018).

O roteiro utilizado contou com dez questões subjetivas, formuladas com base na revisão bibliográfica do referencial teórico, de maneira que as perguntas possam responder de forma satisfatória e completa ao objetivo geral e específicos da investigação. Ele se encontra no apêndice, no final do trabalho.

E, por fim, para analisar os dados, o método escolhido foi o da análise de conteúdo que, segundo Bardin (2011), é um conjunto de técnicas de análise das comunicações, que utiliza-se de procedimentos sistemáticos com a finalidade de obtenção de indicadores (quantitativos ou não) que possibilitem a dedução dos conhecimentos relativos às condições destas mensagens. Diante do exposto, a investigação realizou uma análise das seguintes categorias: inovação, autonomia, propensão a tomar riscos, pró-atividade e agressividade competitiva, constituídas a priori a partir da revisão bibliográfica do tema pesquisado. Em seguida, as mesmas foram analisadas na próxima seção do trabalho.

\section{ANÁLISE DOS RESULTADOS}

A análise dos resultados obedecerá a sequência das perguntas incorporadas ao questionário, tendo como base as categorias que abrangem o estudo.

\section{INOVAÇÃO}

De acordo com o primeiro questionamento, "Como gestor de recursos humanos, você procura utilizar formas inovadoras na sua gestão junto aos colaboradores? Quais?", os posicionamentos dos entrevistados foram as seguintes:

Entrevistada 1: "Sim, descentralização das responsabilidades e atividades, implementação de maior número de reuniões mensais para poder ouvir o feedback dos colaboradores e tentar atender a todos de acordo com suas prioridades, implementação de pautas de solicitações para que seja facilitada a comunicação do colaborador com a gestão."

Entrevistado 2: "Não sei se isso é ser inovador, mas procuro ser um gestor democrático. Ouço os empregados para saber, de fato, no que podemos melhorar e procurar passar um feedback do trabalho deles, de uma forma geral. Acho que nesse sentido ganhamos muito com isso." 
Entrevistado 3: "Sim, procuramos inovar utilizando estratégias de inovação aberta quando procuramos nos mercados projetos inovadores que podem ser aproveitados pela empresa, ou utilizando inovação fechada onde consultados nossos próprios colaboradores produzindo inovações personalizadas que atendem demandas diretas da equipe. A maioria dos nossos projetos utilizam características de inovação pois promovem o uso da tecnologia para aumento da produtividade das ações. Como exemplo utilizamos um plano completo de gestão do conhecimento com base na metodologia de gameficação, onde as atividades realizadas pelo colaborador são pontuadas como em um jogo, assim à medida que - colaborador ganha pontos (acumula conhecimento) ele pode passar de nível (ser promovido)."

Entrevistada 4: "Sim, com anuência da empresa procuro ter como preocupação um ambiente de trabalho com qualidade para os empregados. Muitos deles passam mais horas dos seus dias aqui do que em suas próprias casas. Além disso, há o reconhecimento por ideias ou práticas que façam a diferença para a empresa com premiações para eles e estendidas as suas famílias."

No que diz respeito às respostas desta questão, grande parte dos entrevistados costuma utilizar-se de formas e ações inovadoras junto aos seus colaboradores, tais como: a descentralização das responsabilidades, a utilização de estratégias de inovação aberta e fechada, além da metodologia de gameficação, entre outras. Segundo Longenecker e Schoen (1975), o empreendedorismo está associado à ações inovadoras e/ou criativas, onde envolvem o surgimento de novos produtos, serviços, negócios e até mesmo novos mercados, provocando mudanças estruturais e organizacionais nas organizações. A única exceção foi o entrevistado 2, pois o mesmo apresenta aspectos que são voltados para os tipos de liderança, e não como ações inovadoras aos colaboradores. De forma geral, pode-se identificar nas entrevistas que os gestores de empresas de pequeno e de médio porte apresentam ações empreendedoras inovadoras junto aos seus colaboradores, entregando assim um ambiente com características únicas e com possibilidade de crescimento.

Relativamente ao questionamento 2, "Que tipo de mudanças você realizou na rotina de trabalho para implementar práticas inovadoras? Descreva um pouco sobre elas.", foi possível obter as seguintes declarações:

Entrevistada 1: "Uma das mais importantes foi a empatia, saber ouvir. Existia uma barreira entre gestão e colaborador essa barreira foi quebrada, hoje temos flexibilidade de horários para facilitar compromissos despertando a motivação do mesmo."

Entrevistado 2: "Temos reuniões quinzenais para tratar de diversos temas. Já procurei realizar treinamentos para aperfeiçoamento de todos, além de trabalhar a parte de reconhecimento do trabalho e do diálogo." 
Entrevistado 3: "Colocamos toda a rotina de gestão de pessoas dentro do software assim conseguimos escala e controle na execução das práticas de gestão de pessoas. Assim o uso da tecnologia foi fundamental para gerar inovação, outra rotina importante foi a realização de benchmarking em premiações e certificadoras como FNQ, ISO ou GPTW."

Entrevistada 4: "A prática de treinamentos online é uma realidade, todos os colaboradores realizam capacitações semestrais. Reuniões mensais são realizadas para ouvir o empregado e, ao mesmo tempo, passar feedbacks comportamentais sobre o rendimento apresentado. Além da empresa apostar em uma comunicação ágil e efetiva de modo a evitar qualquer tipo de problemas."

Observa-se que os gestores entrevistados buscam, de forma geral, um aprimoramento junto aos seus colaboradores, apostando em treinamentos (presencial ou online), flexibilidade de horários, priorizando principalmente uma melhor proximidade dos gestores junto aos seus colaboradores, uma atitude simples, mas que impacta de grandiosamente na motivação dos mesmos. Segundo Lumpkin e Dess (1996), a inovação pode ser compreendida como a tendência da organização em investir e prestar apoio a novas ideias, projetos, inovações e/ou criações e aprimoramentos de processos, onde podem resultar em novos produtos e serviços junto ao mercado. Além das práticas citadas anteriormente, pode-se acrescentar a implantação do benchmarking em prêmios e certificações pelos gestores de empresas de médio porte.

\section{AUTONOMIA}

Nesta categoria, de acordo com o questionamento 3 "Você se considera um profissional autônomo? Por quê?", seguem as disposições dos entrevistados:

Entrevistada 1: "Sim, somos uma empresa pequena o dono raramente vem à João Pessoa e ele precisa confiar na gestão toda e qualquer decisão deve ser tomada pela gestão."

Entrevistado 2: "Na medida do possível, sim. Possuo certa credibilidade com os donos do negócio e tenho carta branca para gerir a equipe. Claro, procuro deixá-los a par das minhas decisões, pois não quero passar por cima dos meus superiores."

Entrevistado 3: "Sim, costumo ser proativo na gestão da minha demanda tento sempre está um passo à frente dos prazos de entrega de projetos e tenho tempo para pensar em novas ideias e quando aprovadas tempo para implementação. Como exerce uma função de direção a função de gestão de pessoas ganha bastante autonomia não só pela característica pessoal, mas também pela autonomia institucionalizada na função." 
Entrevistada 4: "Não, apesar da empresa confiar bastante nas minhas decisões e dar condições de realizar bem o meu trabalho, sem intromissões, sigo diretrizes e as políticas organizacionais, pois sei que tenho uma hierarquia acima do meu cargo".

Grande parte dos gestores apresentam autonomia perante as organizações em que atuam. Contudo, nas empresas de pequeno porte, a autonomia é baseada na confiança e na responsabilidade entregue aos gestores. Segundo Lumpkin e Dess (1996, p. 141) "a autonomia se apresenta por um comportamento independente do empreendedor e pela prática de forte liderança por parte deste, refletindo, assim, um comportamento autocrático." Já nas empresas de médio porte, o entrevistado 3 apresenta características fortes de liderança, buscando engajar a sua equipe e cumprir seus prazos e metas com antecedência. A entrevistada 4, demonstra condições para a sua autonomia, todavia não a exerce, preferindo uma atuação seguindo as diretrizes e políticas organizacionais em conjunto com os seus superiores.

No que tange o questionamento 4 "A empresa lhe concede autonomia para a sua gestão à frente do setor de Recursos Humanos? Explique como.", os entrevistados declararam que:

Entrevistada 1: "Sim, tanto no DP como nas práticas do Rh, cargos e salários, saúde como na implementação do plano odontológico para benefícios do colaborador nas atividades com empresas parceiras com: Festa do dia das crianças para filhos dos nossos colaboradores."

Entrevistado 2: "Sim, como mencionei anteriormente, os proprietários confiam bastante no meu trabalho e me deixam a frente de muitas decisões. Procuro fazer o meu trabalho com seriedade, tentando obter o melhor aproveitamento da equipe para colher resultados satisfatórios de desempenho."

Entrevistado 3: "Sim, como tudo na empresa é mensurado (resultados, perdas, ganhos, produtividade etc), sempre que comprovado por meio de análises que o projeto é viável posso implementar as ações sem restrição. E já existem escopos e limites claros definidos para minha atuação."

Entrevistada 4: "Ela oferece condições para que eu realize o meu trabalho sem interferências, porém cabe a mim informar as práticas que exerço em prol do bom funcionamento do setor e da empresa, de um modo geral, haja vista que o RH exerce influência em diversos aspectos organizacionais. Tenho que ter, acima de tudo, bom senso para gerir corretamente o setor."

Diante do exposto pelos entrevistados, percebe-se que ambos os tipos de empresas concedem autonomia ao gestor frente ao setor de RH. Nas empresas de pequeno porte, como citado anteriormente, a gestão tem como base a confiança entre os superiores e os gestores, já nas empresas de médio porte, os gestores 
possuem um escopo de atuação pré-definido para a implantação de projetos e gestão do ambiente. Segundo Lee e Peterson (2000), para a autonomia ser eficaz, os empreendedores devem atuar por meio de culturas que promovam à ação independente, para manter o controle sobre as pessoas e a procura por novas oportunidades.

\section{PROPENSÃO A TOMAR RISCOS}

De acordo com o questionamento 5, "No papel de gestor de RH, com que frequência você toma decisões? Comente esse processo no ambiente de trabalho junto aos colaboradores.", os entrevistados apresentaram os seguintes depoimentos:

Entrevistada 1: "Tomadas de decisão faz parte da minha rotina, como já mencionei sou muito aberta ao diálogo e procuro sempre atender a necessidade do colaborador."

Entrevistado 2: "Constantemente, como os patrões não moram na cidade estou a frente diariamente de várias situações. Por estar na empresa a um tempo considerável, tenho segurança para tomar as decisões."

Entrevistado 3: "Diariamente. Dentro do escopo definido no plano de cargos e salários várias decisões passam pelo gestor de pessoas, como decisão de pré-seleção de colaboradores, aprovação no batismo de novos colaboradores, aprovação das práticas de treinamento, indicação de promoções e demissões de funcionários, aprovação e parecer em análises de desempenho e diversas outras decisões. Existe muito respeito as pessoas no ambiente de trabalho então as decisões devem ser pautadas em um conjunto sólido de valores distribuídos por toda a empresa."

Entrevistada 4: "A decisão final é sempre da diretoria, no entanto sou consultada em diversos aspectos em relação ao corpo funcional da empresa e como ele pode ser melhor aproveitado em práticas e ideias futuras. Me sinto proativa e necessária nesses momentos, vendo a minha contribuição tanto em momentos decisivos como rotineiros."

Observa-se que os gestores dos dois tipos de organizações recorrem a tomada de decisão diariamente, levando em consideração a função de Gestor de $\mathrm{RH}$, pois utilizam-se de cautela para analisar e, consequentemente, tomar decisões para alcançar os objetivos. Declarações que vão ao encontro das afirmações de Miller (1983), cuja propensão a tomar riscos é compreendida como o empenho da organização em realizar projetos arriscados junto aos seus gestores, a fim de atingir os objetivos do negócio. Vale ressaltar que, de acordo com os depoimentos, nas empresas de médio porte, as decisões são regidas por políticas internas e pelo plano de cargos, onde dependendo da organização as decisões finais são tomadas por diretores e/ou encarregados. 
Partindo para o questionamento 6 "Como gestor de RH, você avalia algumas decisões como arriscadas? Por quê? Exemplifique algum caso que aconteceu na empresa.", os relatos colhidos afirmaram:

Entrevistada 1: "Sim, porque todas envolvem pessoas e às vezes finanças, temos que pensar e medir as consequências antes de tomar alguma decisão e agir de forma que os riscos sejam mínimos possíveis, pois ainda somos uma empresa pequena no mercado de João Pessoa. Exemplo algum evento que a gente vai fazer precisamos analisar o quanto vai ser benéfico e se o financeiro suporta. Outra decisão de risco sempre é uma demissão ou admissão, como trabalhamos por demanda essas decisões precisam sempre serem bem pensadas."

Entrevistado 2 : "Acredito que toda decisão que tomamos possui um risco, nem que seja mínimo. Imprevistos sempre podem acontecer, trazendo complicações a planejamentos elaborados com certa antecedência. Uma certa vez, fizemos um planejamento da contratação de mais um funcionário, animados com o clima de abertura da loja, porém analisei a situação e percebi que aquela contratação poderia ser adiada, mesmo com os números me mostrando o contrário. Dei uma recuada e acho que a decisão foi acertada, pois passado o clima de oba-oba da inauguração o movimento estabilizou."

Entrevistado 3: "Sim, demissões e admissões sempre envolvem risco. São decisões que precisam de muita análise e cuidado, poisinterferem de maneira significativa no clima e produtividade da empresa. Dentre as decisões mais difíceis que tomei foi a apresentação da nova estrutura de diretores da empresa, a mudança cultural e de processos era muito grande e poderia provocar um conjunto amplo de efeitos colaterais positivos e negativos."

Entrevistada 4: "Sempre haverá riscos, o mercado é instável, não há segurança. Contratações e demissões, dependendo do contexto e das pessoas envolvidas sempre podem acarretar em consequências não previstas."

A partir dos relatos acima, os entrevistados apontam que algumas das decisões tomadas se caracterizam como de risco, pois em sua totalidade envolvem pessoas, finanças ou imprevistos não provisionados. Dentre os exemplos citados, percebe-se que abrangem situações em que os gestores tiveram que analisar e pontuar cuidadosamente os pontos positivos e negativos ao tomar decisões. Segundo Longenecker e Schoen (1975), confere-se este risco como toda e qualquer iniciativa empreendedora em que envolva grau de risco, de forma que, quanto maior o fator de inovação, maior será a incerteza. 


\section{PRÓ-ATIVIDADE}

De acordo com o disposto no questionamento 7, "Você se considera um gestor de RH proativo? Por quê?", foram recolhidos os seguintes depoimentos:

Entrevistada 1: "Sim, muito desde rotinas administrativas, corro atrás de parcerias para beneficiar minha empresa e meus colaboradores, criamos um lugar de descanso para eles, sou flexível nos horários, busco saídas para possíveis problemas, fazemos reuniões frequentemente, fazemos pesquisa de clima. Me considero sim uma gestora proativa"

Entrevistado 2: "Sim, modéstia à parte estou sempre por perto, acompanhando tudo e observando o trabalho da equipe nos mínimos detalhes. Não é fácil, mas é necessário."

Entrevistado 3: "Sim, sou um gestor sempre satisfeito, mas nunca conformado. A constante busca por melhorias fazem com que a gestão de pessoas seja cada vez mais importante. A qualquer sinal de ampliação de risco, avaliamos a situação e utilização ações mitigadoras e preventivas."

Entrevistada 4: "Sem falsa modéstia, meu sobrenome é trabalho. Não me contento com o "mais ou menos". Um bom profissional de RH atualmente precisa se mostrar multiatarefado. Estou gerindo com o bem mais precioso da empresa, os seus funcionários. Há mais de 8 anos os subsistemas de RH estão todos sob a minha responsabilidade e com orgulho posso afirmar que tenho dado conta do recado."

Diante do exposto, todos os gestores se consideram como proativos, sejam por propor uma maior aproximação junto aos seus colaboradores, pela busca de novas parcerias que possam favorecer a organização ou por estarem em constante busca por melhorias. Um aspecto interessante de se observar nas empresas de médio porte, é que além destas ações tradicionais, os gestores demonstram alguns comportamentos adicionais, como a utilização de ações mitigadoras e preventivas junto a situações de riscos sinalizadas, um conjunto de atitudes simples, mas que pode auxiliar grandemente nas rotinas de trabalho. Justificando assim a visão de Penrose (1959), onde trata-se da importância dos gestores empreendedores para desenvolvimento e crescimento da organização, pois esse profissional possui uma visão e criatividade necessárias para explorar as oportunidades do mercado.

No que concerne ao questionamento 8, "A empresa valoriza a sua proatividade enquanto gestor? Como?", segue os relatos dos entrevistados:

Entrevistada 1: "Não muito, infelizmente, não sei se é porque ainda somos pequenos aqui em João Pessoa ou pela política mesmo da empresa esse ponto é lamentável, nós Gestores somos muito necessários nas empresas." 
Entrevistado 2: "Sim, sou sempre consultado para os projetos futuros, decisões imediatas da loja. Isso me traz uma grande alegria, sentir esse reconhecimento dos proprietários."

Entrevistado 3: "Sim, por meio de promoções e gratificações salariais."

Entrevistada 4: "Me sinto essencial, porém essa valorização nunca foi exposta formalmente. Sinto que sou respeitada, ouvida e as minhas posições são consideradas, dessa forma percebo esse movimento como um reconhecimento implícito."

De acordo com o questionamento, constatou-se que nas empresas de pequeno porte, observa-se que a valorização da proatividade dos gestores não se dá de forma integral, oscilando perante as organizações e suas políticas adotadas, quesito este que pode influenciar no desempenho dos gestores, pois se torna um aspecto desmotivador no reconhecimento de suas atribuições. Segundo Martens e Freitas (2008), a proatividade pode ser crucial para uma OE, pois ela sugere uma perspectiva de visão diante das mudanças e surgimentos de novos mercados e ideias. Já nas empresas de médio porte, observa-se que os gestores entrevistados demonstram ou identificam a valorização de sua proatividade, mesmo que em certos casos ela se dê de forma implícita, enquanto que em outros, de maneira geral, por meio de promoções e gratificações.

\section{AGRESSIVIDADE COMPETITIVA}

De acordo com o questionamento 9, "Você se considera um gestor de RH competitivo? Por quê?", os participantes da pesquisa mostraram:

Entrevistada 1: "Muito extremamente, não sei ficar parada estou sempre envolvida com projetos de marketing, divulgação e parcerias com empresas maiores, como já falei, oferecendo descontos do nosso serviço, esse trabalho eu mesma faço. Foco muito em resultados."

Entrevistado 2: "Muito, não me contento com o razoável. Trabalho todos os dias para ter a melhor equipe na nossa loja, a mais qualificada. Tento estar perto para desenvolvê-los da melhor maneira possível."

Entrevistado 3: "Sim. Pensamos a curto e longo prazo, como tornar nossas equipes mais competitivas e produtivas. Analisamos tendências e cenários para tomar decisões mais assertivas ao longo do processo gerencial de pessoas. Tendo orientar nosso modelo de negócios, metas e planejamento a condições de ampla competitividade de mercado." 
Entrevistada 4: "Sim, porque amo o que faço, o meu trabalho é exercido com garra e vontade e luto para ter o meu setor sempre em destaque na empresa."

Observa-se que, em sua totalidade, todos os entrevistados se consideram como gestores competitivos, nas empresas de pequeno porte, justificam-se por meio de envolvimento em projetos, pela qualificação dos seus colaboradores e pelo foco no resultado. Já os gestores das empresas de médio porte, além destas ações demonstram preocupações tanto a curto, quanto a longo prazo com os seus colaboradores, além de analisarem tendências e cenários ao longo dos processos gerenciais de pessoas, de forma a orientar da melhor forma possível o modelo de negócio, suas metas e planejamentos junto ao mercado. Compreendendo o que Covin e Slevin (1989, p. 71)) conceituavam como "capacidade da organização de responder a tendências e demandas que existem no ambiente de mercado".

Por fim, segue o questionamento 10, "A empresa estimula o setor de recursos humanos a ter essa postura junto aos colaboradores e ao mercado? Como?", onde os entrevistados dispuseram da seguinte maneira:

Entrevistada 1: "Um pouco, creio que a forma de estimular que a empresa achou foi me dando mais autonomia fazendo parte do todo da empresa."

Entrevistado 2: "Sim, até porque o nosso ramo é muito concorrido, logo temos que ter uma postura competitiva mesmo, para ganhar espaço. Sabendo disso, tentamos aperfeiçoar a equipe constantemente."

Entrevistado 3: "Sim, competitividade e produtividade são bases do nosso comportamento."

Entrevistada 4: "Queremos ser reconhecidos na área, para tanto a empresa busca incentivar os funcionários com bonificações, recompensas e outros estímulos para levantar esse espírito competitivo. Porém, ainda há muito o que ajustar, o mercado é feroz e, por vezes, muitos ficam tentados a migrar para a concorrência. Nesse sentido, procuramos trabalhar de forma a reter os nossos melhores talentos para termos uma equipe preparada e qualificada no trabalho. Não é fácil, mas o RH consegue ser presente e atuante."

Os gestores entrevistados dos dois tipos de empresas apontam o devido reconhecimento do setor de RH por parte das organizações em que trabalham, mesmo que se manifestem em diferentes formas. De acordo com Chen e Hambrick (1995), a agressividade competitiva é considerada com a tendência da organização em responder às ações dos concorrentes e do mercado. Além das ações tradicionais citadas, as empresas de médio porte utilizam-se de incentivos aos seus colaboradores, seja através de bonificações, recompensas e através de outros estímulos, de forma a tentar manter sempre os seus colaboradores, entregando assim características únicas. 


\section{CONSIDERAÇÕES FINAIS}

Diante do estudo realizado, buscou-se analisar a aplicação da Gestão de Recursos Humanos como uma nova estratégia para os gestores das empresas de pequeno e médio porte da cidade de João Pessoa - PB. Partindo deste princípio, foi possível formular a seguinte problemática: como a gestão de $\mathbf{R H}$ pode representar uma estratégia empreendedora para os gestores de pequenas e médias empresas da cidade de João Pessoa - PB?

Para responder ao questionamento mencionado acima, averiguou-se três objetivos específicos neste estudo. No que refere-se ao primeiro, identificar as práticas de Gestão de RH mais utilizadas pelos gestores responsáveis pelo setor, percebeu-se que os entrevistados, independente de serem empresas de pequeno ou de médio porte, fazem uso de práticas tradicionais, tais como recrutamento e seleção, treinamentos, feedback, motivação de seus colaboradores, entre outros. Além de fazer uso de práticas inovadoras como a gameficação, descentralização de processos/atividades e o uso de estratégias de inovações personalizadas.

Já o segundo objetivo específico, verificar as ações empreendedoras que têm relação com os Recursos Humanos, com base nos entrevistados e sua utilização das dimensões da orientação empreendedora, foi possível perceber que a maioria das empresas disponibilizam recursos e oferecem autonomia suficiente para os gestores tomarem decisões, tendo em vista que todas envolvem análise e nível de risco, conforme o setor. Desta forma, percebe-se que as ações disponibilizadas pela OE auxiliam de forma construtiva na gestão de recursos humanos e agregam valor nas competências que compõem o seu modelo de gestão.

No que abrange o terceiro objetivo específico, examinar a relação entre empreendedorismo e Gestão de RH no contexto das pequenas e médias empresas, a gestão de RH vem apresentando um crescimento significativo e agregando cada vez mais obrigações junto às organizações. De forma que, atualmente, exerce além das suas atividades tradicionais, uma visão e comprometimento estratégico com a organização e com a sua cultura, buscando compreender os colaboradores, suas necessidades e os processos em que estão envolvidos. Em meio a este cenário surge a $\mathrm{OE}$, uma ferramenta que pode ser utilizada tanto em empresas de pequeno, quanto de médio porte, de modo que pelos gestores entrevistados percebe-se a adesão conjunta destas capacidades e ações frente ao setor de RH e frente a empresa, em que a empresa concede as ferramentas necessárias para colocálas em prática, proporcionando inovação e renovação aos objetivos e aos riscos enfrentados.

Logo, ao analisar o objetivo geral deste estudo, pode-se perceber o quanto o RH passou e vem passando por diversas mudanças e transformações, saindo de um setor totalmente burocrático, para de fato gerir pessoas, de uma forma cada vez mais estratégica e empreendedora se tornando atualmente um 
dos setores mais importantes em uma organização, seja ela de pequeno ou de médio porte, contribuindo assim com o crescimento da empresa e aumentado a sua competitividade.

Foi constatado por meio das respostas dos gestores entrevistados que a orientação empreendedora no RH vem sendo incorporada nas organizações e pelos seus gestores, estando cada vez mais presente e atuante. Tanto nas empresas de pequeno e médio porte, os gestores vêm utilizando as dimensões da OE no seu dia-adia, concedendo autonomia e recursos para isto, agregando grandemente na sua gestão. Contudo, nem sempre as empresas valorizam ou mesmo reconhecem essas competências em seus gestores, sejam por possuírem uma cultura organizacional que não contemple e/ou valorize tais aspectos, ou por algumas empresas não possuírem um plano de carreira com projeções de crescimento.

Por fim, como fator limitador deste estudo, verificou-se que a disponibilidade dos gestores para responderem as entrevistas nos períodos estipulados foi o maior desafio encontrado, pois acarretou em uma certa demora ou não retorno por parte de alguns deles, o que acabou resultando em uma dependência exagerada ou atraso de certos estágios do artigo.

Como proposta para estudos futuros, sugere-se que esta pesquisa seja realizada novamente, porém direcionada para segmentos específicos do mercado. Organizações do segmento de prestação de serviços, hotelaria, comércio, indústria, educação, entre outros. Além disso, o estudo pode ser realizado em diferentes localidades do país, em municípios ou regiões diversificadas, de forma a compreender a realidade em outros contextos.

\section{REFERÊNCIAS}

ALBUQUERQUE, L. G.; LEITE, N. P. (Orgs.). Gestão de pessoas: perspectivas estratégicas. São Paulo: Atlas, 2009.

BARDIN, L. Análise de conteúdo. São Paulo: Edições 70, 2011.

BRUYAT, C.; JULIAN, P. Defining the field of research in entrepreneurship. Journal of Business Venturing, v. 16, p. 165-180, 2000.

CAMPOS, N. A.; DUARTE, F. J. da C.M. A dimensão social da atividade empreendedora. Cadernos de Psicologia Social do Trabalho, v. 16, n. SPE, p. 13-23, 2013.

CASSON, M.; YEUNG, B.; BASU, A.; WADESON, N. The oxford handbook of entrepreneurship. Oxford University Press, 2006.

CATTANI, A. Trabalho e tecnologia: dicionário crítico. Porto Alegre: Editora Universidade, 1997. 
CHEN, Ming-Jer; HAMBRICK, Donald C. Speed, stealth, and selective attack: how small firms differ from large firms in competitive behaviour. The Academy of Management Journal, v. 38, n. 2, p. 453-482, April 1995.

CHIAVENATO, I. Gestão de Pessoas: ${ }^{a}$. Edição totalmente e aplicada. Rio de Janeiro: Campus, 2005.

CHIAVENATO, I. Recursos humanos: o capital humano das organizações. 9. ed. rev. atual. Rio de Janeiro: Elsevier, 2009.

CHRISTENSEN, P. V; ULHOI, J. P; MADSEN, H. The entrepreneurial process in a dynamic network perspective: A review and future directions for research. Copenhagen:The Aarhus school of business, 2002.

COVIN, J. G.; SLEVIN, D. P. Strategic management of small firms in hostile and benign environments. Strategic Management Journal, v. 10, n. 1, p. 75-87, 1989.

DEMO, G. Políticas de gestão de pessoas nas organizações: papel dos valores pessoais e da justiça organizacional. 3. ed. São Paulo: Atlas, 2010.

DIAS, J. N. O RH que gera lucro. Revista Você RH, 2015. Disponível em: < http://exame. abril.com.br/revista-voce-rh/edicoes/36/noticias/o-rh-que-gera-lucro>. Acesso em: 16 ago. 2018.

DORNELAS, J. Empreendedorismo: transformando idéias em negócios. Rio de Janeiro: Elsevier, 2008.

DRUCKER, P. Inovação e espírito empreendedor. São Paulo: Thomson, 2001.

GARTNER, W. B. A conceptual framework for describing the phenomenon of new venture creation. Academy of Management Review, v. 10, n. 4, p. 696-706, 1985.

GRÉGOIRE, D. A.; NOËL, M. X.; DÉRY, R.; BÉCHARD, J-P. Is There Conceptual Convergence in Entrepreneurship Research? A Co-Citation Analysis of Frontiers of Entrepreneurship Research, 1981-2004. Entrepreneurship Theory and Practice, v. 30, n. 3, p. 333-373, 2006.

HAYTON, J. C. Promoting corporate entrepreneurship through human resource management practices: A review of empirical research. Human Resource Management Review, v. 15, n. 1, p. 21-41, 2005.

HASHIMOTO, M. Organizações Intra-Empreendedoras: Construindo a Ponte entre Clima Interno e Desempenho Superior. 2009, 363 f. Tese (Doutorado em Administração de empresas) - Fundação Getúlio Vargas, São Paulo, 2009. 
IBGE. Instituto Brasileiro de Geografia e Estatística. As Micro e Pequenas Empresas Comerciais e de Serviços no Brasil. Disponível em: <https://biblioteca.ibge.gov.br/ visualizacao/livros/liv1898.pdf>. Acesso em: 30 set. 2018.

JULIEN, P. A. Empreendedorismo regional a economia do conhecimento. São Paulo: Saraiva, 2010.

LANDSTROM, $H_{.}$; BENNER, M. Entrepreneurship research: a history of scholarly migration. In: LANDSTROM, H.; LOHRKE, F. Historical foundations of entrepreneurship. Northhampton: Edgard Elgar, 2010.

LANDSTRÖM, H.; HARIRCHI, G.; ASTRÖM, F. Entrepreneurship: Exploring the Knowledge base. Research Policy, v. 41, n. 7. p. 1154-1181, set. 2012.

LEE, S. M.; PETERSON, S. J. Culture, Entrepreneurial orientation, and global competitiveness. Journal of World Business, v. 35, n. 4, p. 401-416, 2000.

LONGENECKER, J.; SCHOEN, J. E. The essence of entrepreneurship. Journal of small business management, v. 13, p. 23-32, 1975.

LUMPKIN, G. T.; DESS, G. G. Clarifying the entrepreneurial orientation construct and linking it to performance. Academy of Management Review, v. 21, n. 1, p. 135-172, 1996.

MACORE, S. A. Origem e evolução de Recursos Humanos. Ebah, 2016. Disponível em: <http://www.ebah.com.br/content/ABAAAhBDYAL/origem-evolucao-recursos humanos>. Acesso em: 02 set.2018

MARRAS, Jean Pierre. Gestão de pessoas em empresas inovadoras. São Paulo: Futura, 2005.

Administração de recursos humanos: do operacional ao estratégico. 15.ed. - São Paulo: Saraiva, 2017.

MARTENS, C. D. P; FREITAS, H. Orientação Empreendedora nas organizações e a busca de sua facilitação. GESTÃO.Org - Revista Eletrônica de Gestão Organizacional, v.6, n.1, Jan/Abr 2008.

MAS-TUR, A. What to Avoid to Succeed as an Entrepreneur. Journal of Business Research, v. 68, p. 2.279-2.284, 2015.

McClelland, D. C. (1972). A sociedade competitiva: realização e progresso social. Rio de Janeiro:Expressão e Cultura.

MILLER, D. The correlates of entrepreneurship in three types of firms. Management Science, v. 29, n. 7, p. 770-791, 1983. 
PENROSE, Edith T. The Theory of the Growth of the Firm. Oxford, England: Oxford University Press, 1959.

RICHARDSON, ROBERTO JARRY; PFEIFFER, DIETMAR KLAUS. Pesquisa social: métodos e técnicas. 4. ed. São Paulo: Atlas, 2017.

ROBBINS, S. P. Comportamento Organizacional. São Paulo: Pearson, Prentice Hall, 2002.

SADLER-SMITH, E.; EL-KOT, G.; LEAT, M. Differentiating work autonomy facets in a nonWestern context. Journal of Organizational Behavior, v. 24, n. 6, p. 709-731, ago. 2003.

SCHUMPETER, J. Capitalism, Socialism, and Democracy. Harper and Row, New York, 1950.

SEBRAE. Serviço Brasileiro de Apoio às Micro e Pequenas Empresas. Sobrevivência das empresas no Brasil. . Disponível em: <https://m.sebrae.com.br/Sebrae/Portal\%20 Sebrae/Anexos/sobrevivencia-das-empresas-no-brasil-102016.pdf>. Acesso em: 20 jul. 2018.

SEBRAE. Serviço Brasileiro de Apoio às Micro e Pequenas Empresas. Sobrevivência das empresas no Brasil. . Disponível em: <http://blog.sebrae-sc.com.br/numero-deempregados-receita-bruta-para-mei-me-epp/>. Acesso em: 30 set. 2018.

SELTISIKAS, P.; LYBEREAS, T. The culture of entrepreneurship: towards a relational perspective. Journal of Small Business and Entrepreneurship, v. 13, n 2, p. 25-36, 1996.

STEVENSON, H. H.; JARILLO, J. C. A paradigm of entrepreneurship: entrepreneurial management. Strategic Management Journal, v. 11, n. 5, p. 17-27, 1990.

TARABISHY, A.; SOLOMON, G.; FERNALD, L. W. Jr.; SASHKIN, M. The Entrepreneurial Leader's Impact on the Organization's Performance in Dynamic Markets. The Journal of Private Equity, v. 8, n. 4, p. 20-29, 2005.

TEGON, Cezar Antonio. Gestão de Pessoas na Era da Informação. Rh Portal, 2015. Disponível em: < https://www.rhportal.com.br/artigos-rh/gesto-de-pessoas-na-erada-informao/>. Acesso em: 16 ago.2018.

Recebido em: 08/02/2019.

Aceito em: 07/06/2019. 